\title{
Reliability Importance Measures considering Performance and Costs of Mechanical Hydraulic System for Hydraulic Excavators
}

\author{
Wenting Liu $\mathbb{D}^{1},{ }^{1}$ Qingliang Zeng $\mathbb{D}^{1,2,3}$ Lirong Wan, ${ }^{1}$ Jinxia Liu, ${ }^{1,2}$ and Hanzheng Dai $\mathbb{D}^{1}$ \\ ${ }^{1}$ Department of Mechanical and Electronic Engineering, Shandong University of Science and Technology, Qingdao, \\ Shandong 266590, China \\ ${ }^{2}$ Shandong Province Key Laboratory of Mine Mechanical Engineering, Shandong University of Science and Technology, \\ Qingdao 266590, China \\ ${ }^{3}$ Department of Information Science and Engineering, Shandong Normal University, Jinan, Shandong 250358, China
}

Correspondence should be addressed to Qingliang Zeng; qlzeng@sdust.edu.cn

Received 15 October 2021; Accepted 29 November 2021; Published 7 January 2022

Academic Editor: Chun-xi Yang

Copyright (C) 2022 Wenting Liu et al. This is an open access article distributed under the Creative Commons Attribution License, which permits unrestricted use, distribution, and reproduction in any medium, provided the original work is properly cited.

\begin{abstract}
Although some reliability importance measures and maintenance policies for mechanical products exist in literature, they are rarely investigated with reference to weakest component identification in the design stage and preventive maintenance interval during the life cycle. This paper is mainly study reliability importance measures considering performance and costs $\left(\mathrm{RIM}_{\mathrm{PC}}\right)$ of maintenance and downtime of the mechanical hydraulic system (MHS) for hydraulic excavators (HE) with energy regeneration and recovery system (ERRS) and suggests the scheduled maintenance interval for key components and the system itself based on the reliability $R_{i}(t)$. In the research, the required failure data for reliability analysis is collected from maintenance crews and users over three years of a certain type of hydraulic excavators. Minitab is used for probable distribution estimation of the mechanical hydraulic system failure times, and the model is verified to obey Weibull distribution. RIM PC $_{\text {is }}$ calculated by multiplying the reliability $R_{i}(t)$ and weighting factor $W_{i}$ and then compared with other classical importance measures. The purpose of this paper is to identify the weakest component for MHS in the design stage and to make appropriate maintenance strategies which help to maintain a high reliability level for MHS. The proposed method also provides the scientific maintenance suggestion for improving the MHS reliability of the HE reasonably, which is efficient, profitable, and organized.
\end{abstract}

\section{Introduction}

With development of society and the progress of science and technology, crisis of lack of energy and serious environmental pollution has become increasingly prominent. As the second-largest internal combustion engine product in addition to autoindustry, construction machinery pollutes environment more seriously than other industries, since its large engine capacity, high oil consumption, and high emissions. To achieve energy conservation, pollution reduction, and sustainable development, various energy-saving technologies have been applied in construct machinery, such as hybrid, energy recovery, electronic control, and new energies. Among these, the favorite for customers and manufacturers is energy recovery technology, for its low cost and high production efficiency. The hydraulic system of con- struction machines become more complicated when upgraded with energy recovery unit; hence, quality and reliability analyses for complex hydraulic system become the most important task in the stages of design, running, and maintenance. Importance measures are utilized to evaluate the effect of parts on a system when single or multiple parts fail or their states change; they are functions of reliability parameters and system structures. In system design stage, the weakest part of system could be sought out by importance analysis, which applied for supporting system promotion from a design perspective. In system operational stage, the preventive maintenance policies or replacement scheme can be performed in right time by means of important measures analysis, which could ensure system operated normally.

In this study, importance measure calculation of individual component which belongs to the subsystem is used to 
measure the effectiveness of the reliability for complex mechanical hydraulic system with energy recovery system. Reliability models are established for important measure calculation, and some assumptions are made as follows; a binary system is formed from two functional states: perfect functionality and complete failure. For energy regeneration and recovery system (ERRS) of construction machinery have the characteristics of multicircuit, nonlinearity, and uncertainty, it is difficult to do reliability analysis and reliability design optimization in practical production. The $\mathrm{RIM}_{\mathrm{PC}}$ is proposed for importance measure, and prevention scientific maintenance is suggested for improving the ERRS reliability of the HE reasonably. It is significant to do the important analysis for key subsystems of complex system, for manufacturers to put their effort to the analyzed main parts.

The major contributions of this paper include the following:

(1) Assessment index $\mathrm{RIM}_{\mathrm{PC}}$ is presented to evaluate system reliability; it is convenient and practical for maintenance crew

(2) Develop a new reliability importance measure and identify the manufacturing bottleneck of energy regeneration and recovery system assessment of construction machinery in the design stage

(3) Suggest appropriate preventive maintenance interval of system for maintenance crew to keep high reliability for new system

The upcoming sections will cover the following: Section 2 reviews prime importance measures briefly for the binary and multistate systems. In Section 3, a new reliability importance measure is proposed, and preventive maintenance interval is suggested. An energy regeneration and recovery system of hydraulic excavator is taken as illustration in Section 4 to explain how the proposed measure works and then discovers by new method, and various importance measures are compared and discussed. The conclusion comes in Section 5 .

\section{Review of Importance Measures for Binary and Multistate Systems}

Numerous importance measures and reliability assessment methods have been developed in recent years, like Birnbaum method and the optimization measures, Monte Carlo simulation, Markov chain, and Fault Tree Analysis, most of which are utilized in the field of electronics and aerospace $[1,2]$.

This section reviews kinds of classic importance measures in reliability system design. Birnbaum proposed the classic binary importance measures of components in a coherent system in the 1960s [3], categorizing importance measures into three classes, namely, the structure importance measure, the reliability importance measure, and the lifetime importance measure. Recent advances and extensions to multistate components on importance measures have been successfully developed and applied for various purposes as shown in the literature [4].

Lambert conducted on fault trees for decision-making in system analysis and criticality importance measure [5]; Vesely and Fussell implemented Fussell-Vesely importance measure $[6,7]$, concerned with component failures contributing to system failure, which refers to the probability of system failure when at least one of the minimum cut sets fails, and represented the ratio of the minimum cut set of component failure to system failure. Armstrong and Hong introduced joint reliability importance of components and $k$ -out-of- $n$ systems and analyzed the influence of primary and secondary components on system reliability $[8,9]$.

Binary decision diagram is a method proposed by Akers in the 1970s and developed in recent years based on fault tree analysis [10], for the advantages such as in low computational complexity and easy implementation, this methodology is popularly utilized in practical applications [11-17].

Barlow and $\mathrm{Wu}$ defined a system state function for coherent systems with multistate components and investigated its properties. They supposed that the results for the theory of binary structures could be applied in multistate component fault by natural extensions in terms of system function [18].

Lisnianski et al. defined multistate systems (MSSs) as they had different performance levels and several failure modes with various effects on the entire system's performance. He reviewed methods and tools used in the field of reliability assessment, optimization, and application [19]. The research team also did a lot of work in solving a family of MSS problems, such as structure optimization, optimal expansion, maintenance optimization, and optimal multistage modernization. And they also proposed an approach based on the universal generating function technique for the evaluation of some commonly used importance measures. [20, 21] presented a new method of dynamic availability and perform ability analysis for a large-scale multistate system based on robotic sensors [22, 23].

The composite importance measure proposed by Ramirez-Marquez and Coit about importance measures was to disclose critical part in a system so that the maintenance crew could rank the components in a system by means of their impact to performance reduction and production loss [24].

Natvig presented a probability model of operations and maintenance, described various types of MSSs, and searched on the measures of component importance in nonrepairable and repairable multistate strongly coherent systems [25, 26].Wu et al. proposed new utility importance of a component state in MSS, clarified the difference with importance measures suggested by William S. Griffith, and overcome some drawbacks. They also discussed the impact of an individual part to the performance utility of an MSS, so as to optimize it [27].

Zhang developed a heuristic policy for maintaining multistate systems for allocating maintenance resources to systems with higher importance [28]. The criticalities of different parts and the long-term effects of successful maintenance activities on the throughput of a production system 


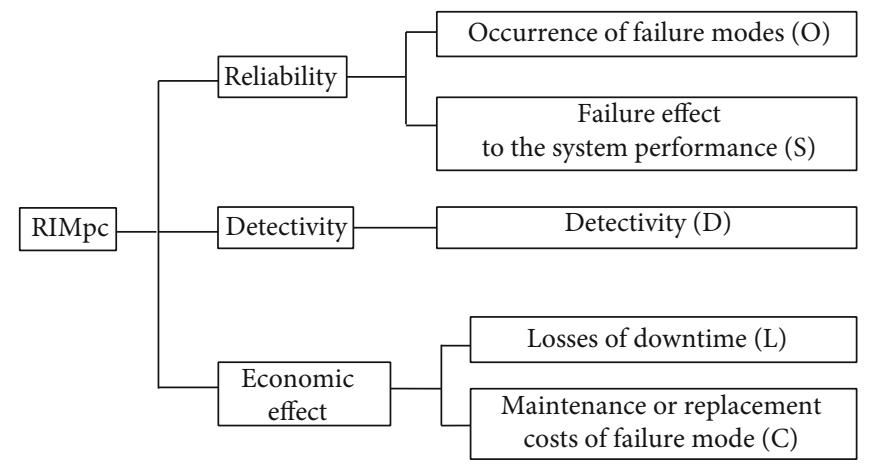

FIgURE 1: Reliability importance measure.

in a certain period to be solved by Ahmed and Liu and two types of importance measures prioritize the critical parts in the maintenance schedule to be presented [29]. Dao and Zuo presented some models based on reliability analysis to figure out the reliability of a complex system and assigned the reliabilities of its parts in a range of states varying from perfect functioning to complete failure [30].

Do and Bérenguer developed a novel time-dependent importance measure that could be utilized to rank the parts or groups of parts through their ability and to promote the system reliability for a given mission according to the conditional reliability evaluation of the system [31]. Borgonovo introduced the differential importance measure, a new sensitivity measure for probabilistic safety assessment [32, 33], proposed a new importance measure for time-independent reliability analysis, and offered a rank comparison with other time-dependent and time-independent reliability importance measures [34].

Peng et al. proposed two new importance measures for systems with S-independent degrading components and with S-correlated degrading components considering the continuously changing status of the degrading components and the correlation between components [35]. Ahmadi et al. evaluated the reliability, availability, and maintainability of the tunneling equipment and analyzed the material hauling system in an earth pressure balance tunnel boring machine [36]. Proper importance measures can help to identify design weakness or operation bottlenecks, conduct optimal modifications for system upgrades and maintenance, and provide information about the importance of components on the system performance, which includes reliability, availability, productivity, safety, and detectability [37].

\section{Proposed Method}

In this paper, a new reliability importance measure considering performance of mechanical hydraulic system (MHS) and cost of maintenance and downtime of construction machine caused by MHS' failures is proposed for the whole machine whose reliability and performance can be improved effectively if the weakest part is predicted as early as possible. For complex systems, limited resources are supposed to allocate according to how important the components are to the system in the design, enhancement, and maintenance stage efficiently. In this study, an optimal strategy is implemented economically to identify the improvable part for system performance taking into system reliability, operation performance, maintenance cost, and losses in downtime account. Figure 1 is block diagram of the proposed reliability importance measure.

3.1. Explanation of the Principle of Reliability Importance Measures. All components and a system under consideration have the set of reliability states $s=\{0,1, \cdots, K\}$ and $s \geq 1$. The state of component $i$ is ordered as $s_{i}(k) . s_{i}(0)$ denotes component $i$ as complete failure, $s_{i}(k)$ denotes component $i$ as perfect function, and states degrade with time $t$. The probability matrix $P$ of the components is presented as $P$; for all components, $k \in s, 0 \leq p_{i k} \leq 1$, and in each row $P$ adds up to 1 .

$$
\begin{aligned}
& P=\left[p_{i k}\right]=\left[\begin{array}{ccc}
p_{00} & \cdots & p_{0 K} \\
\vdots & \ddots & \vdots \\
p_{K 0} & \cdots & p_{K K}
\end{array}\right], \\
& \operatorname{RIM}_{\mathrm{PC}}=R_{i}(t, \cdot) .
\end{aligned}
$$

$R_{i}(t, \cdot)=\left[R_{i}(t, 0), R_{i}(t, 1) \cdots, R_{i}(t, k)\right]$ is called the multistate reliability function of a component $i, R_{i}(t, \cdot)=P$, where $R_{i}(t, \cdot)$ is calculated based on the Weibull model of components' historical failure data. The Weibull distribution is used to transform the data effectively to Weibull model in machine reliability analysis, which shows effective ability of describing the wear-out failures and the product lifetime. The mathematical expressions of the Weibull distribution are shown in Appendix A. Reliability analysis based on Weibull approach probably be considered to generate better solution when system reliability expectation is high [38-40]. The weighting factor $W_{i}$ in Equation (1) is used to calculate RIM $_{\mathrm{PC}}$ which takes performance and cost of machine operation into account in after-sales stage. Suppose the $i$ th component has $n$ kinds of failure modes, where $W_{i}$ is defined as follows:

$$
W_{i}=\sum_{j=1}^{n} S_{i j} O_{i j} D_{i j} L_{i j} C_{i j}
$$


TABLE 1: Suggested ranking system for the occurrence of failure modes [37].

\begin{tabular}{lccc}
\hline Rank $\left(O_{i j}\right)$ & Comment & Failure frequency & Coefficient \\
\hline 10 & Extremely high & $\geq 0.2$ & 0.1 \\
9 & Very high & $\geq 0.1$ & 0.2 \\
8 & Repeated failures & $\geq 0.05$ & 0.3 \\
7 & High & $\geq 0.03$ & 0.4 \\
6 & Moderately high & $\geq 0.02$ & 0.5 \\
5 & Moderate & $\geq 0.01$ & 0.6 \\
4 & Relatively low & $\geq 0.005$ & 0.7 \\
3 & Low & $\geq 0.003$ & 0.8 \\
2 & Remote & $\geq 0.0005$ & 0.9 \\
1 & Nearly impossible & $\geq 0.0001$ & 1.0 \\
\hline
\end{tabular}

$S_{i j}:$ The severity of the failure modes effect to the system performance, 10 ranks

$O_{i j}$ :Occurrence of the failure modes, 10 ranks

$D_{i j}$ :Detectability of the failure modes, 10 ranks

$L_{i j}$ :Losses of downtime under the failure mode, losses of downtime of the machine include economic losses of the systems stop running, 10 ranks

$C_{i j}$ :Costs of the maintenance or replacement when the failure happens, 10 ranks.

The detailed ranking of $S, O, D, L$, and $C$ is shown in Tables 1-5, which are worked out with the database belonging to HE manufacture. It can also be used for other construction machines after being revised.

3.2. New Approach for ERRS Preventive Maintenance Interval. It is necessary to make proper preventive maintenance strategies in the design stage to reduce machine downtime, increase operation time, and improve the availability of the equipment during use. There are three main types of maintenance in machine life cycle management. One is routine maintenance; it is easy to implement with less cost; the second one is restorative maintenance, which requires low cost and short time; and the third one is replacement maintenance, which replaces the parts that have lost their functions and makes the equipment repair as new. Hydraulic excavators are usually used in harsh environment with higher failure rates, so that the economic benefits for users are affected if as the traditional maintenance plan.

According to the calculated reliability of the old excavator hydraulic system, new maintenance method is put forward to guide the maintenance of energy recovery system, reduce the failure rate, improve the service life, and make users gain greater economic benefits. Moreover, the study results can help to improve excavators manufactures' maintenance management, to change users' one-sided understanding of excavator hydraulic system management, operation, maintenance, and other technical requirements, and further, to improve the reliability of the whole machine.

According to the standard regulation of the construction equipment maintenance, the driver performs routine maintenance per shift, and maintenance crew implement restor-
TABLE 2: The ranking of downtime losses caused by the failure mode.

\begin{tabular}{lcc}
\hline Losses & Ranking & Coefficient \\
\hline$<0.5$ & 1 & 1.0 \\
$0.5-1$ & 2 & 0.9 \\
$1-1.5$ & 3 & 0.8 \\
$1.5-2.0$ & 4 & 0.7 \\
$2.0-2.5$ & 5 & 0.6 \\
$2.5-3.0$ & 6 & 0.5 \\
$3.0-3.5$ & 7 & 0.4 \\
$3.5-4.0$ & 8 & 0.3 \\
$4.0-4.5$ & 9 & 0.2 \\
$4.5-5.0$ & 10 & 0.1 \\
\hline
\end{tabular}

ative maintenance per 200 hours, replacement maintenance per 600 hours, and overhaul per 1800 hours. Most of the manufacturers recommended maintenance intervals at operation time of machines are 250 hours, 500 hours, 1000 hours, 2000 hours, 4000 hours, and 5000 hours, respectively. The predictive maintenance process proposed in this paper is shown in Figure 2.

Routine maintenance $T_{\mathrm{M}}$ is the same as traditional maintenance per shift, and preventive maintenance $T_{\mathrm{P}}$ is defined as per 500 hours. Restorative maintenance $T_{\mathrm{F} 1} T_{\mathrm{F} 2}$

$T_{\mathrm{F} n}$ is determined by the value of $R_{i}(t)$ at the operation time $t$. If the $R_{i}(t)$ of one component in the system is lower than the $R_{\text {set }}(t)$, which was described in the paper [38], the first restorative maintenance $T_{\mathrm{F} 1}$ should be taken. Since there is time-delay for $R(t)$ rising, $R(t)$ will decrease first and then rise after restorative maintenance but not as high as initial value. $T_{\mathrm{F}}$ is decreasing with increasing usage time of the machine, so all the values of the $T_{\mathrm{F} n}$ are different and gradually decrease. Replacement maintenance $T_{R}$ is implemented at the time when the components' $R(t)$ achieves the minimum value as the preset. Overhaul period $T_{\mathrm{D}}$ is determined as

$$
T_{\mathrm{D}}=\left(\frac{T}{t_{0}} \cdot \frac{\gamma}{\beta-1}\right)^{1 / \beta}
$$

$T:$ Denotes the average maintenance time

$t_{0}$ :Denotes the average routine maintenance time

$\beta$ :Denotes the estimated shape parameter of maintenance parts.

The scheduled maintenance time of ERRS is shown in Figure 3.

\section{Unit Case Study}

4.1. Description of Energy Regeneration and Recovery System for Hydraulic Excavator. The case studied in this paper MHS with energy regeneration and recovery system (ERRS) which is newly developed and used in hydraulic excavators. The ERRS is designed based on the balancing theory; the schematic principle of HE with ERRS is shown in Figure 4 [41, 
TABLE 3: The ranking of components maintenance or replacement costs $\left(10^{3} \mathrm{RMB}\right)$.

\begin{tabular}{lcc}
\hline Costs & Ranking & Coefficient \\
\hline$<1.0$ & 1 & 1.0 \\
$1.0 \sim 5.0$ & 2 & 0.9 \\
$5.0 \sim 10.0$ & 3 & 0.8 \\
$10.0 \sim 15.0$ & 4 & 0.7 \\
$15.0 \sim 20.0$ & 5 & 0.6 \\
$20.0 \sim 25.0$ & 6 & 0.5 \\
$25.0 \sim 30.0$ & 7 & 0.4 \\
$31.0 \sim 35.0$ & 8 & 0.3 \\
$35.0 \sim 40.0$ & 9 & 0.2 \\
$40.0 \sim 45.0$ & 10 & 0.1 \\
\hline
\end{tabular}

42]. Reversing valves 6,11 , and 12 are moving to the left side when the boom goes down, then the hydraulic oil(HO) is pumped into the rod cavity of main boom cylinder (RCMBC) 10 through reversing valve 6 . One branch of $\mathrm{HO}$ is carried into the two rod cavity of balance cylinders (RCBC) 9 via reversing valve 12; another branch of $\mathrm{HO}$ in the piston cavity of main boom cylinder (PCMBC) 10 returns to the tank by reversing valve 11; and the selfgravity potential energy generated during the boom down is accumulated into hydraulic accumulator (HA) as hydraulic energy via valve 7 [39]. The hydraulic accumulator (HA) is used for storing and releasing energy; accumulator's pressure acting on the boom always shows itself as a balancing weight for the load [43].

Reversing valves 6,11 , and 12 are all linked on the right side when the boom goes up; then, $\mathrm{HO}$ is pumped from the tank into the PCMBC 10 by reversing valve $6, \mathrm{HO}$ accumulated in accumulator is released into RCBC 9, and $\mathrm{HO}$ in RCMBC 10 and RCBC 9 return to the tank through reversing valve 11 and valve 12 , respectively [42].

For a complex mechanical hydraulic system, the system reliability is based on the component reliability. It is critical to know the importance of each part of MHS; severe failure of the component may lead to collapse of the whole system if it had not been discovered in time. Various factors in the process of maintenance must be considered, such as maintenance cost, difficulty, and time [44, 45].

For example, leakage of hydraulic cylinder will reduce the work efficiency of MHS; before any obvious fault occurs, it must be anticipated with preventive measures. Any one tiny failure of subsystem may cause the failure of the entire system if there are no backups for these components.

4.2. Schematic Diagram of the Mechanical Hydraulic System. A schematic diagram of the MHS of ERRS is illustrated in Figure 5. Some components of the system are unlikely to fail during the machine lifetime, as known from engineering experience, like throttle valves and solenoid valves. Therefore, these kinds of components are not conducted importance analysis in this work. However, servo valves, cylinders, pumps, reversing valves, booms, tubes, and accumulators, which with higher failure rates throughout the whole energy recovery and release process, are most likely to be vulnerable components.

In actual operation of excavators with ERRS, all the hydraulic components do not have backups due to high cost. How to balance the system reliability improvement and cost reduction is very important for excavator manufactures.

4.3. Calculation of Reliability Importance Measures. To study the importance and identify the weakest components of the MHS, this paper collects the failure data of the 30 Ton HE for three years from the maintenance database. The number of working HE in all is 973, recorded by GPS, and the number of failure data of the mechanical hydraulic system is 197 .

In this case, the following assumptions are made for mechanical hydraulic components and system:

(I) All components have two states: functioning and failed

(II) All components are in a perfect state at the beginning

(III) Behaviors of components are mutually statistically independent

(IV) All the components are repairable to new when they fail

As a universally adaptive distribution, the Weibull law is widely used to describe the life distribution of mechanical products for modeling the failure behavior of components. Minitab is used to fit all the failure times of MHS and to test the Anderson-Darling goodness. Anderson-Darling (AD) test is a kind of square-variance statistics. Although the statistical process is slightly complicated, it can maintain good performance when using the small sample size. The fitted results are shown in Table 6 and Figure 6. As shown in Table 7, the three-parameters Weibull distribution has the smallest AD statistics, with the value of 0.493 , so it has been clearly seen that the best goodness of fit is the threeparameter Weibull distribution for ERRS, and the components of this ERRS testified to be fitted as a threeparameter Weibull distribution well.

This paper uses the mean rank order methods to calculate the empirical cumulative distribution function of each component of MHS and the reliability at 3000 hours, because the warranty services of repair are during 3000 hours for machine manufactures.

$$
\begin{aligned}
F_{m}(t) & =\frac{j\left(f_{m}\right)-0.3}{n+0.4}, \\
j\left(f_{m}\right) & =j\left(f_{m-1}\right)+n_{f m} \bullet N\left(f_{m}\right), \\
N\left(f_{m}\right) & =\frac{(n+1)-j\left(f_{m-1}\right)}{1+\left(n-n_{f m}-n_{s u}\right)} .
\end{aligned}
$$$$
j\left(f_{m}\right)\left(m=1,2, \cdots n_{f}\right)
$$$$
n: \text { Sample number }
$$$$
n_{f} \text { :Failure number }
$$$$
n_{s} \text { :Unfailed number. }
$$ 
TABLE 4: Suggested ranking system for the severity of failure modes [38].

\begin{tabular}{|c|c|c|c|}
\hline Failure effect & Failure criterion & Ranking & Coefficient \\
\hline \multirow{2}{*}{$\begin{array}{l}\text { Inconsistent with the safety legislation or the } \\
\text { regulations }\end{array}$} & $\begin{array}{c}\text { Hazardous without warning potential safety, health, or } \\
\text { environmental issue }\end{array}$ & 10 & 0.1 \\
\hline & $\begin{array}{c}\text { Failure will occur with warning potential safety, health, or } \\
\text { environmental issue }\end{array}$ & 9 & 0.2 \\
\hline \multirow[b]{2}{*}{ Disruption or decline to facility function } & The machine runs malfunctioning & 8 & 0.3 \\
\hline & $\begin{array}{l}\text { The machine runs properly but moderate disruption to facility } \\
\text { function }\end{array}$ & 7 & 0.4 \\
\hline \multirow{2}{*}{ Disruption or decline to secondary function } & Some portion of secondary function is lost & 6 & 0.5 \\
\hline & Moderate disruption to secondary function & 5 & 0.6 \\
\hline \multirow{2}{*}{$\begin{array}{l}\text { Appearance or noise and other functions is } \\
\text { poor }\end{array}$} & Some portion of process is delayed & 4 & 0.7 \\
\hline & Most users (>75\%) likely to complain & 3 & 0.8 \\
\hline \multirow{2}{*}{$\begin{array}{l}\text { No discernible effect on safety, environment, or } \\
\text { mission }\end{array}$} & More than half $(>50 \%)$ of the users likely to complain & 2 & 0.9 \\
\hline & a few users (>25\%) likely to complain & 1 & 1.0 \\
\hline
\end{tabular}

TABLE 5: Detectivity evaluation criteria.

\begin{tabular}{|c|c|c|c|}
\hline Detectivity & Control & Ranking & Coefficient \\
\hline Absolute uncertainty & $\begin{array}{c}\text { No control. Design control will not and/or cannot detect a potential cause/mechanism } \\
\text { and subsequent failure mode }\end{array}$ & 10 & 1.0 \\
\hline Very remote & $\begin{array}{c}\text { Very remote chance the design controls will detect a potential cause/mechanism and } \\
\text { subsequent failure mode }\end{array}$ & 9 & 0.9 \\
\hline Remote & $\begin{array}{c}\text { Remote chance the design controls will detect a potential cause/mechanism and } \\
\text { subsequent failure mode }\end{array}$ & 8 & 0.8 \\
\hline Very low & $\begin{array}{c}\text { Very low the design controls will detect a potential cause/mechanism and subsequent } \\
\text { failure mode }\end{array}$ & 7 & 0.7 \\
\hline Low & $\begin{array}{c}\text { Low chance the design controls will detect a potential cause/mechanism and subsequent } \\
\text { failure mode }\end{array}$ & 6 & 0.6 \\
\hline Moderate & $\begin{array}{c}\text { Moderate chance the design controls will detect a potential cause/mechanism and } \\
\text { subsequent failure mode }\end{array}$ & 5 & 0.5 \\
\hline Moderately high & $\begin{array}{c}\text { Moderately high chance the design controls will detect a potential cause/mechanism } \\
\text { and subsequent failure mode }\end{array}$ & 4 & 0.4 \\
\hline High & $\begin{array}{c}\text { High chance the design controls will detect a potential cause/mechanism and subsequent } \\
\text { failure mode }\end{array}$ & 3 & 0.3 \\
\hline Very high & $\begin{array}{c}\text { Very high chance the design controls will detect a potential cause/mechanism and } \\
\text { subsequent failure mode }\end{array}$ & 2 & 0.2 \\
\hline Almost certain & $\begin{array}{c}\text { Design controls will almost certainly detect a potential cause/mechanism and } \\
\text { subsequent failure mode }\end{array}$ & 1 & 0.1 \\
\hline
\end{tabular}

The parameters $\beta, \gamma$, and $\eta$ of cylinders, pump, boom, reversing valve, tubes, and hydraulic system are fitted by Origin. Figure $7(\mathrm{~b})$ shows cylinders' $R_{i}(t)$ changes with operation time, $R_{c i}(t)=0.9311$ when after 3000 hours operation time. Figure $7(\mathrm{c})$ shows pumps' $R_{p i}(t)$ changes with operation time, $R_{p i}(t)=0.9798$ when after 3000 hours operation time. Figure $7(\mathrm{~d})$ shows the reversing valves' $R_{R i}(t)$ changes with operation time, $R_{R i}(t)=0.9826$ when after 1500 hours operation time, for no more failure data about reversing valves from 1500 to 3000 hours, so here, $R_{R i}(t)=0.9826$ is reckoned stayed there ever until 3000. Figure $7(\mathrm{e})$ shows booms' $R_{B i}(t)$ changes with operation time, $R_{B i}(t)=0.9301$ when after 3000 hours operation time. Figure $7(\mathrm{f})$ shows the high-pressure tubes' $R_{T i}(t)$ changes with operation time,
$R_{T i}(t)=0.9385$ when after 2000 hours operation time, for no more failure data about reversing valves from 2000 to 3000 hours, so here, $R_{R i}(t)=0.9385$ is reckoned stayed there ever until 3000. Figure 7 (a) shows the hydraulic systems' $R(t)$ changes with time, $R(t)=0.7636$ when after 3000 hours operation time. And parameters $\beta, \gamma$, and $\eta$ values are known from Figure 7 . Then, $R_{i}(t)$ is calculated by the parameters, the $R_{i}(t)$ of the accumulator and servo valve is calculated by Equation (4) for its few failure numbers (as is shown in Table 8).

The importance of components $\left(I_{\mathrm{PC}}\right)$ is obtained by (1) and (2); they are listed in Table 9. $s_{i k}, o_{i k}, d_{i k}, l_{i k}$, and $c_{i k}$ are designated based on Tables 1-5. The cylinder, pump, and boom have two kinds of failure modes; the 


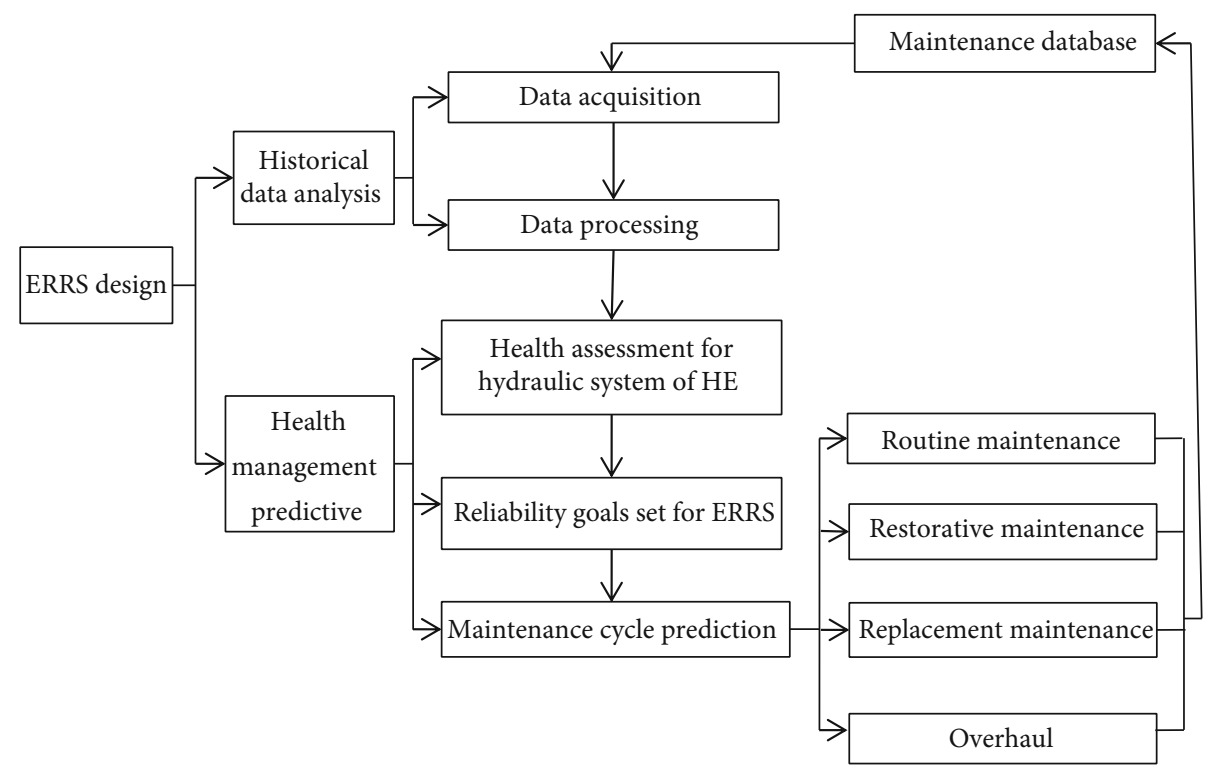

FIGURE 2: Predictive maintenance process of ERRS.

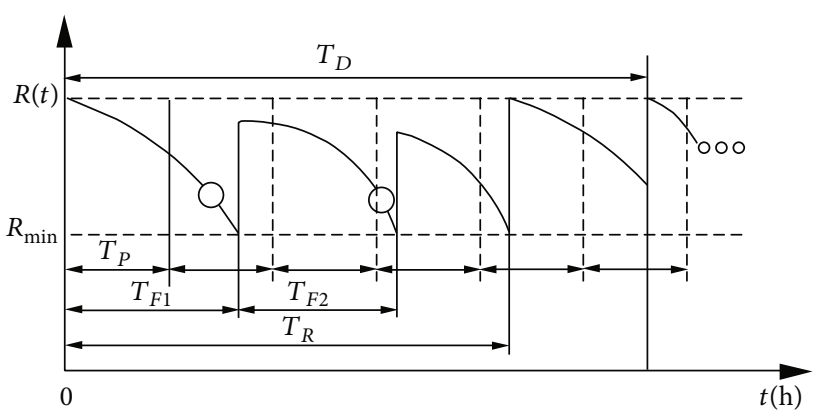

FIGURE 3: Scheduled maintenance time of ERRS.

accumulator, servo valve, reversing valve, and tube only have one failure mode.

As shown in Table 10, the component boom and accumulator have the largest and smallest importance ranking order, respectively, in all different importance measures. This means the boom is the least reliable unit, and the accumulator is the most reliable unit in the MHS. The other component ranking orders change as importance measures change, but the components importance ranking order is completely the same in the method Time Integral Importance Measures (TIIM) and the Criticality Reliability Importance of Component for system failure.

$I_{\mathrm{TIIM}}$ is used to estimate components' importance better in their lifecycle and seek out the most responsible component for subsystem performance loss while ignoring the effects from the costs of the maintenance and downtime by the component failure modes. The criticality timedependent lifetime importance for system failure at time $t\left(I_{\mathrm{cf}}\right)$ is defined as the probability when a component failure causes the given system failure; it does consider the performance losses and costs in the process of systems or products operating. The traditional Birnbaum importance measures do not consider the criticality and the variety of mean lifetime of a system caused by components.
The proposed method in this study considers the severity of the components failure, occurrence rate of the different components failure mode, difficulty level to detect the failure modes, maintenance costs, and breakdown losses when the components failure modes occur. All these aspects are expected to be taken into account in the new system design stage based on the predecessor. The RIM $_{\mathrm{PC}}$ can evaluate the importance of complex mechanical hydraulic system components more simply and effective by historical database compared with other methods. From the definition of RIM $_{\mathrm{PC}}$, it can be used to conduct the importance evaluations not only in multistate system but also in binary system. Therefore, the conclusions derived from binary-state systems can also be used for multistate ones.

4.4. Suggestion about the Optimization of ERRS Design and Maintenance. According to the $\mathrm{RIM}_{\mathrm{PC}}$ value of components of MHS shown in Table 9 and the ranking order shown in Table 10, accumulator and servo valve have higher reliability but lower failure rate. So, they are lower importance components in MHS boom, and cylinders have lower reliability but higher failure rate; they are higher importance components in MHS. The ranking order of pump, reversing valve, and tube is 3,4 , and 5 , respectively.

Through the analysis of historical failure database, the main failure modes of the boom are fracture on the root and welds cracking between the side plates, because fatigue strength is insufficient and badly soldered. In MHS, a new structure of boom has been developed since balance cylinders increase, so methods of robust design optimization in the design stage and enhancement of welding quality in the manufacturing stage should be taken to the boom reliability promotion.

The main failure modes of cylinder include crack, leakage, abrasion, and creep. Dominant reasons for the failures are encounter external impact, instantaneous high pressure, hydraulic oil pollution, and unreasonably kinematic pair 


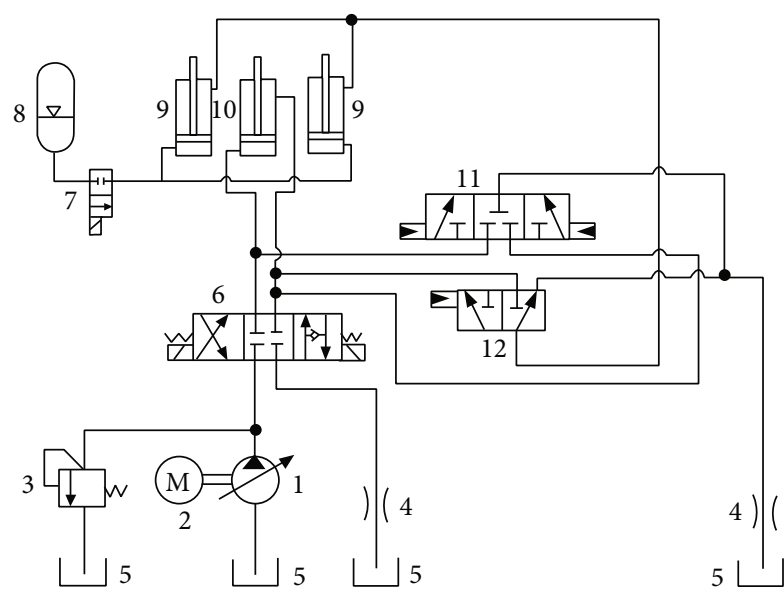

FIGURE 4: The schematic principle of ERRS. 1: pump; 2: engine; 3: relief valve; 4 : throttle valve; 5 : oil tank; $6,7,11,12$ : reversing valves; : hydraulic accumulator; 9; balance cylinders; 10: boom cylinder.

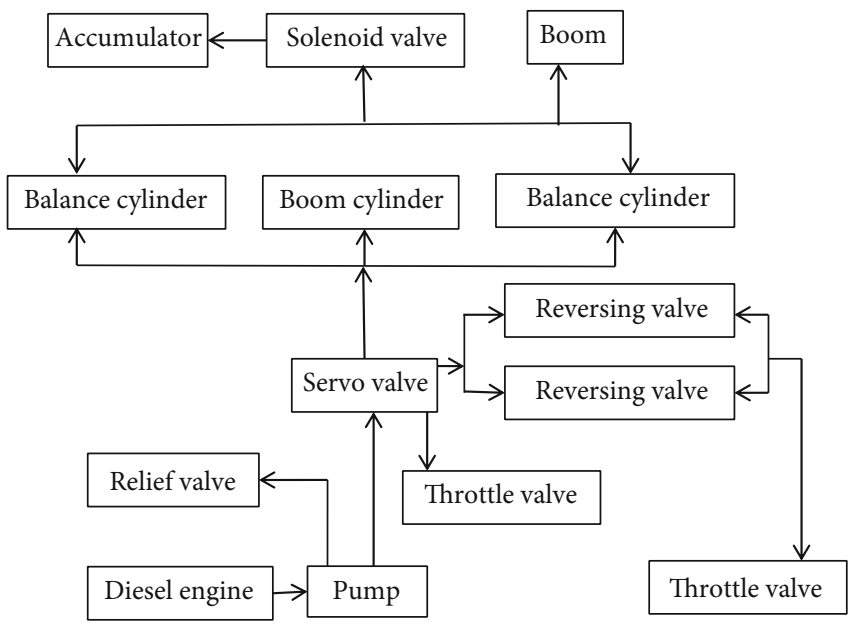

FIGURE 5: Block diagram of the hydraulic system.

clearances, respectively. A protective board suggested to be added on the top of HC which suffers intense impact easily and reduces the instantaneous high pressure caused by energy released from accumulator to the system in the design stage. Promoting assembling accuracy and strengthening the final inspection on the assembly line are also good choice for reliability improvement.

The main failure modes of the tubes are leakage and burst. The main reason of the failures is that overloaded transient impacts pressure in high-pressure tubes, which should be improved in MHS. The abnormal vibration of the hydraulic piston pump causes the leakage, noise, and cracking of the pump body; most of them occurred after 2000 hours of operation time. And when the occurrence is lower at the ranking 0.7 , we suggest changing the maintenance interval to enhance pump reliability. The occurrence of reversing valve leakage can be reduced by optimizing seal quality; the failures of the accumulator and servo valve have occurred accidentally, with little effect on the reliability of the HEs. Further tracing will be performed.
TABLE 6: The number of failure for each component.

\begin{tabular}{lc}
\hline Component & Failure number \\
\hline Cylinders & 44 \\
Accumulator & 1 \\
Servo valve & 3 \\
Pump & 21 \\
Boom & 81 \\
Reversing valve & 12 \\
Tubes & 35 \\
\hline
\end{tabular}

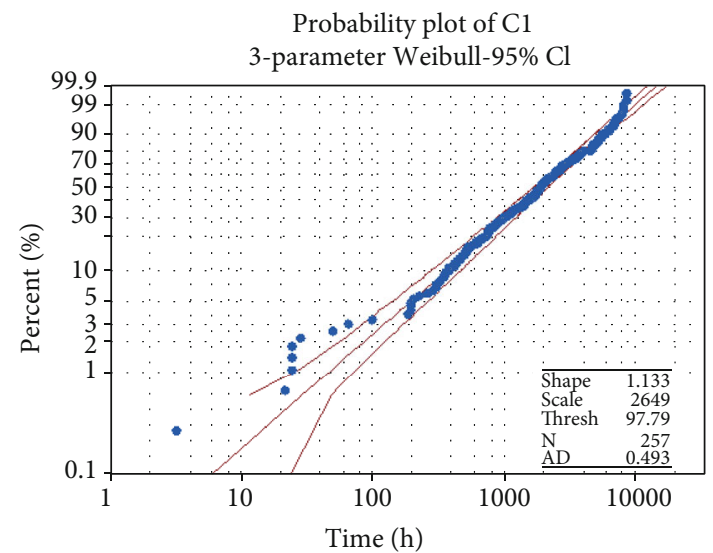

Figure 6: Probability plot of the hydraulic system of HE.

TABLE 7: Failure time distribution AD test for HS of HE.

\begin{tabular}{lc}
\hline Distribution & $\mathrm{AD}$ \\
\hline Weibull & 0.720 \\
3-parameter Weibull & 0.493 \\
Normal & 3.152 \\
Lognormal & 1.817 \\
3-parameter lognormal & 0.991 \\
Gamma & 0.598 \\
Exponential & 3.026 \\
2-parameter exponential & 1.554 \\
Small extreme value & 15.805 \\
Large extreme value & 3.854 \\
Logistic & 7.529 \\
Loglogistic & 1.525 \\
3-parameter Loglogistic & 1.374 \\
\hline
\end{tabular}

4.5. Explanation of Scheduled Maintenance Time for Key Components of ERRS and System Itself. In this section, the scheduled maintenance time of boom will be shown, since it ranks the first in the importance list of MHS.

Routine maintenance $T_{\mathrm{M}}$ is set as the same as traditional maintenance time 8 hours per shift, and preventive maintenance $T_{\mathrm{P}}$ is chosen as per 500 hours.

Restorative maintenance $T_{\mathrm{F} 1}$ of boom is the time when the value of $R_{\text {set }}$ decreases to 0.9 , so $T_{\mathrm{F} 1}$ is determined with parameters' estimated value of $\beta, \gamma$, and $\eta$. It is 

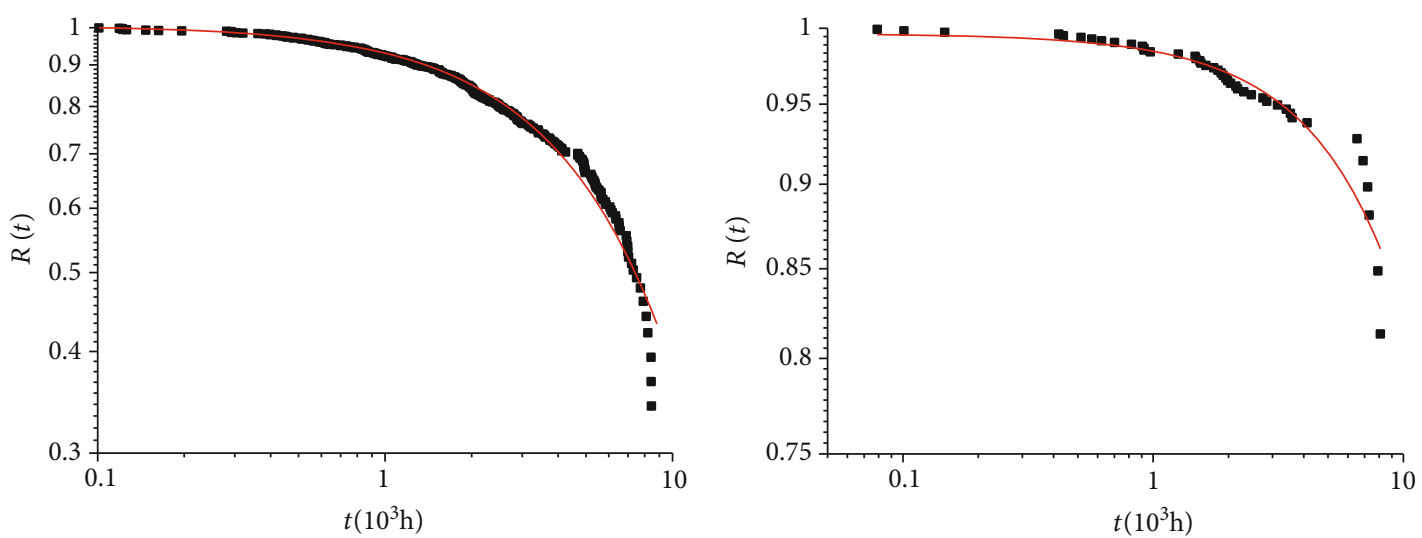

- $\mathrm{R}(t)$ of hydraulic system Fitting line of $R(t)$

- $R(t)$ of cylinder Fitting line of $R(t)$

(a)

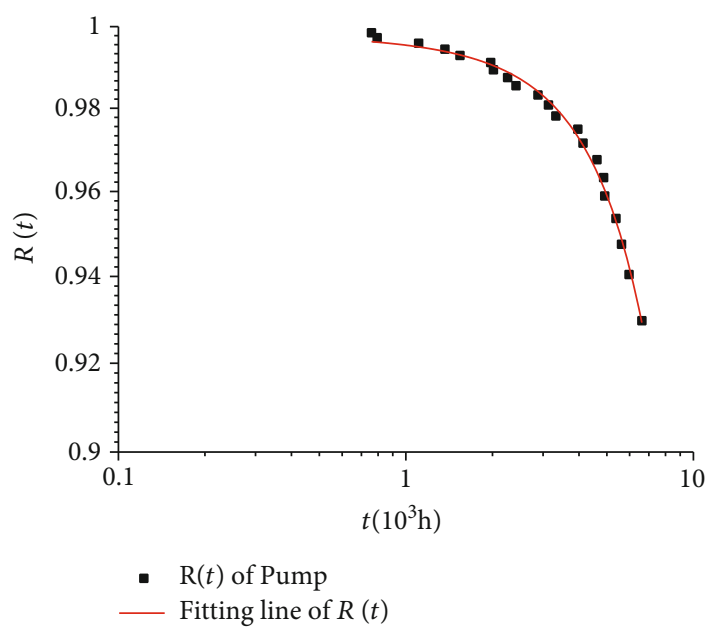

(b)

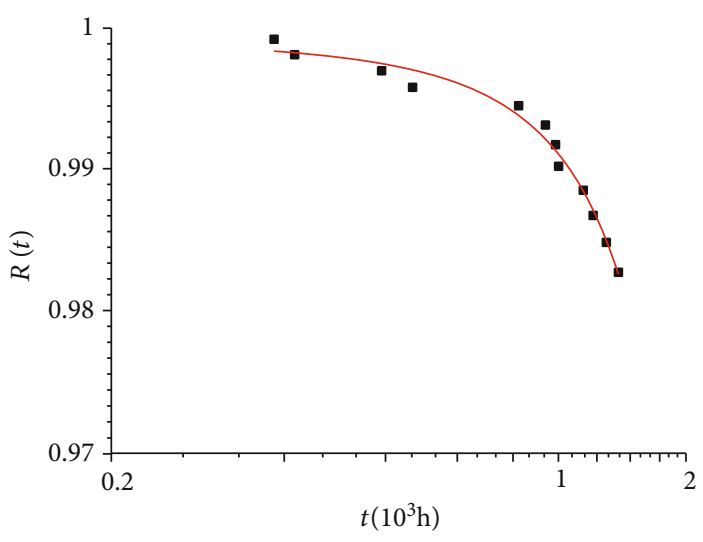

- $\mathrm{R}(t)$ of reversing valve Fitting line of $R(t)$

(c)

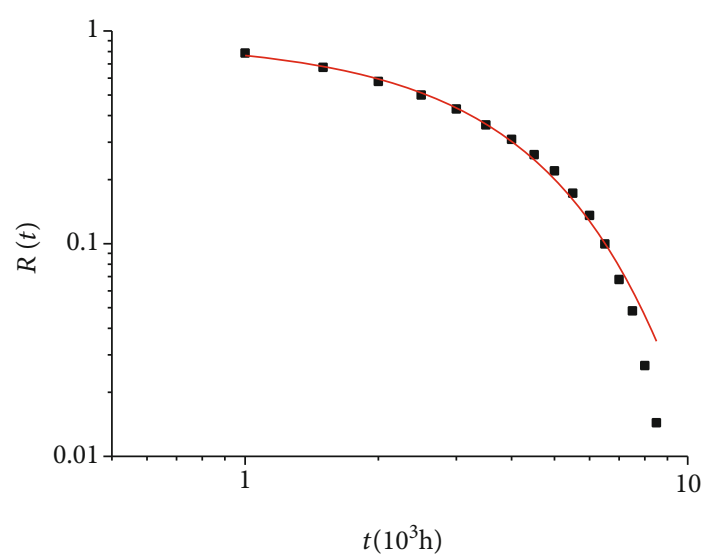

(d)

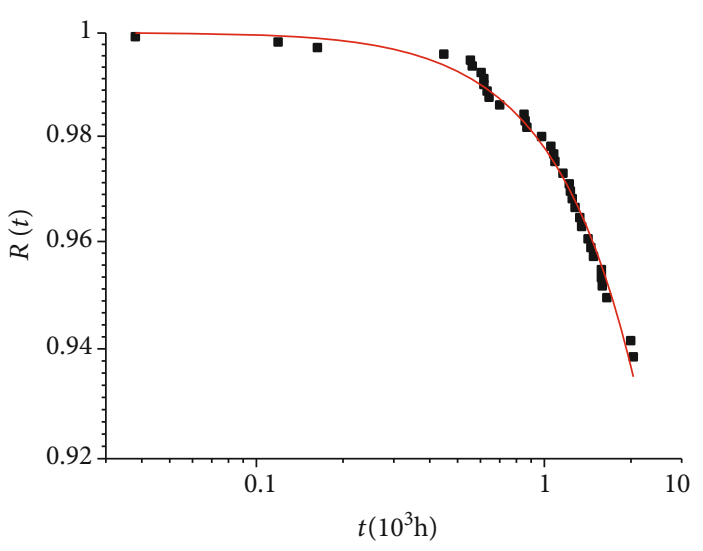

- $\mathrm{R}(t)$ of boom Fitting line of $R(t)$

- $\mathrm{R}(t)$ of tube

— Fitting line of $R(t)$

(e)

(f)

FIgURE 7: Reliability of the hydraulic system and key components.

approximately 3900 working hours. $R_{\min }$ of boom is set as increasing $20 \%$ as we have 0.5960 in Table 8 , so the value $R_{\min }$ of boom is 0.7152 , and replacement maintenance time $T_{\mathrm{R}}$ is approximately 7000 working hours. Overhaul period $T_{\mathrm{D}}$ of ERRS is determined as Equation (3). Parameters $\gamma=101$ and $\beta=1.08$ are obtained from Figure $7(\mathrm{a})$, 
TABLE 8: Components reliability at $t=3000$ hours.

\begin{tabular}{lcccccc}
\hline No. & Component $(i)$ & $\beta$ & $\gamma$ & $\eta$ & $F_{i}(t)$ & 0.0458 \\
\hline 1 & Cylinders & 1.2689 & -438.33 & 38267.0 & 0.9542 \\
2 & Accumulator & $/$ & $/$ & $/$ & 0.0010 & 0.9990 \\
3 & Servo valve & $/$ & $/$ & 22680 & 0.0021 & 0.0170 \\
4 & Pump & 2.8252 & -2374.7 & 4362.3 & 0.9979 \\
5 & Boom & 1.5815 & -884.82 & 13075.2 & 0.9830 \\
6 & Reversing valve & 1.6789 & 383.92 & 12108.0 & 0.0649 & 0.1143 \\
7 & Tubes & 1.4985 & 37.88 & & 0.9351 \\
\hline
\end{tabular}

TABLE 9: Components importance considering performance and costs at $t=3000$ hours.

\begin{tabular}{|c|c|c|c|c|c|c|c|}
\hline Components & $R_{i}(t)$ & $s_{i k}$ & $o_{i k}$ & $d_{i k}$ & $l_{i k}$ & $c_{i k}$ & $\mathrm{RIM}_{\mathrm{PC}}$ \\
\hline \multirow[t]{2}{*}{ Cylinder } & 0.9542 & 0.3 & 0.5 & 0.7 & 0.7 & 0.8 & 0.2364 \\
\hline & & 0.5 & 0.6 & 0.7 & 0.9 & 1.0 & \\
\hline Accumulator & 0.9990 & 0.9 & 0.9 & 0.7 & 0.7 & 0.9 & 0.3569 \\
\hline Servo valve & 0.9979 & 0.7 & 0.8 & 0.6 & 0.8 & 1.0 & 0.2682 \\
\hline \multirow[t]{2}{*}{ Pump } & 0.9830 & 0.3 & 0.6 & 0.9 & 0.4 & 0.4 & 0.2483 \\
\hline & & 0.4 & 0.7 & 0.9 & 0.9 & 1.0 & \\
\hline \multirow[t]{2}{*}{ Boom } & 0.5960 & 0.2 & 0.4 & 0.9 & 0.6 & 0.2 & 0.0963 \\
\hline & & 0.7 & 0.3 & 0.9 & 0.9 & 0.9 & \\
\hline Reversing valve & 0.9351 & 0.7 & 0.6 & 0.9 & 0.8 & 0.9 & 0.2545 \\
\hline Tube & 0.8857 & 0.4 & 0.4 & 0.9 & 1.0 & 1.0 & 0.2551 \\
\hline
\end{tabular}

TABle 10: Components Importance for different methods at $t=3000$ hours.

\begin{tabular}{lcccccccc}
\hline Component & IB & Ranking & ITIIM & Ranking & Icf & Ranking & RIMPC & Ranking \\
\hline Cylinder & 0.0643 & 5 & 169.44 & 3 & 0.0131 & 3 & 0.2364 & 2 \\
Accumulator & 0.0007 & 7 & 193433.7 & 7 & 0.000003 & 7 & 0.3569 & 7 \\
Servo valve & 0.0339 & 2 & 4254.42 & 6 & 0.0009 & 6 & 0.2682 \\
Pump & 0.0464 & 4 & 1624.55 & 5 & 0.0038 & 4 & 0.2483 & 3 \\
Boom & 0.0973 & 1 & 30.299 & 1 & 0.0283 & 1 & 0.0963 \\
Reversing valve & 0.0462 & 3 & 990.35 & 4 & 0.0034 & 5 & 0.2545 & 4 \\
Tube & 0.0777 & 6 & 50.698 & 2 & 0.0203 & 2 & 0.2551 & 5 \\
\hline
\end{tabular}

so $T_{\mathrm{D}}=7760$ working hours, where $T$ is the average maintenance time 100 working hours, and $t_{0}$ is the average routine maintenance time 8 working hours.

\section{Conclusion}

This paper mainly discusses the $\mathrm{RIM}_{\mathrm{PC}}$ (reliability importance measures based on performance and costs of maintenance and downtime). Firstly, the definition of RIM $_{P C}$ of MHS' components is presented. Secondly, the proposed method is verified by the type of MHS with ERRS which belongs to 30 Ton HE. Thirdly, several classical importance measures are compared with the proposed method, and pros and cons are analyzed.

The major conclusions are summarized as follows:

(1) Although a components' deterioration from function to failure will go through many states, only functioning and failure are considered in the process of machine using, therefore, the multistate system has been simplified to a binary system for reliability importance analysis. $\mathrm{RIM}_{\mathrm{PC}}$ can be used to estimate the component importance better in its lifecycle and seek out the most important component for system reliability. Then, more attention can be paid to the most important one to improve system performance and reliability efficiently

(2) $\mathrm{RIM}_{\mathrm{PC}}$ can be used to estimate the importance of complex MHS' components of existing product and predict the reliability of the new-generation product based on existing product's historical failure data. It is also feasible to guide the designers to obtain some clues of reliability allocation in the design stage, to identify what is the root cause for the failure of the part at different operation stage, and to improve the robustness performance of the part in time 
(3) And to guide the maintenance crew in assigning maintenance resources to achieve higher performance in a relatively long term for new systems and new products

(4) Determination of preventive maintenance interval for key components of MHS and system itself based on the historical reliability of them in the design stage can help maintenance crew to keep HE with ERRS functioning effectively

(5) Since the proposed importance measures are developed to evaluate components in a fixed construction machine HE, more research work should be done to find the effects to structural changes, product performance, and reliability improvement in future studies

\section{Appendix}

\section{A. A Detailed Description Is Given}

If the failure behavior of component $I$ described by Weibull stochastic process, its lifetime follows a probability density function is shown as

$$
f(t)=\frac{\beta}{\eta}\left(\frac{t-\gamma}{\eta}\right) \exp ^{-((t-\gamma) / \eta)^{\beta}} .
$$

The probability distribution function is given by:

$$
F(t)=1-\exp \left[-\left(\frac{t-\gamma}{\eta}\right)^{\beta}\right] .
$$

The reliability of component can be then evaluated by:

$$
R(t)=\exp \left[-\left(\frac{t-\gamma}{\eta}\right)^{\beta}\right],
$$

where $\eta, \beta$, and $\gamma$ denote the scale, shape, positional parameters of the components.

\section{List of Symbols}

HA: Hydraulic accumulator

HC: Hydraulic cylinders

ERRS: Energy regeneration and recovery system

MSSs: Multistate systems

FMEA: $\quad$ Failure mode and effect analysis

PCMBC: Piston cavity of main boom cylinder

$F_{m}(t): \quad$ Cumulative failure distribution function

$W_{i}: \quad$ Weighting factor of component $i$

$S_{i j}$ : The serious of the failure modes effect to the system performance failure modes $j$ for component $i$

$O_{i j}$ : $\quad$ Occurrence of the failure modes $j$ for component $i$

$D_{i j}$ : $\quad$ Detectability of the failure mode $j$ for component $i$

$L_{i j}: \quad$ Losses of downtime under the failure mode $j$ for component $i$
$C_{i j}: \quad$ Costs of the maintenance or replacement when the failure happens

HE: $\quad$ traditional excavators

HO: $\quad$ Hydraulic oil

$R_{i}(t): \quad$ Reliability of component $i$ at time $t$

$s_{i}(t): \quad$ Reliability states of component $i$

RCMBC: Rod cavity of main boom cylinder

RCBC: Rods cavity of balance cylinders

$\beta$ : $\quad$ Shape parameter of Weibull distribution

$\eta$ : $\quad$ Scale parameter of Weibull distribution

$\gamma: \quad$ Location parameter of Weibull distribution

$j\left(f_{m}\right): \quad$ Average number of the failure time

$n$ : $\quad$ Sample number

$n_{f}: \quad$ Failure number

$n_{s}: \quad$ Unfailed number

$T_{\mathrm{M}}$ : $\quad$ Routine maintenance

$T_{\mathrm{P}}$ : $\quad$ Restorative maintenance

$T_{\mathrm{R}}$ : Replacement maintenance

$T_{\mathrm{D}}$ : Overhaul period

$T: \quad$ Average maintenance time

$t_{0}$ : Average routine maintenance time.

\section{Data Availability}

The data used to support the findings of this study are available from the corresponding author upon request.

\section{Conflicts of Interest}

The authors declare that there are no conflicts of interest regarding the publication of this paper.

\section{Acknowledgments}

This work is supported by Shandong Provincial Natural Science Foundation (grant no. ZR2019BEE066), Applied Basic Research Project of Qingdao (grant no. 19-6-2-68-cg), Shandong Provincial Natural Science Foundation (grant no. ZR2020ME085), and Shandong Province Key Laboratory of Mine Mechanical Engineering (No. 2019KLMM204).

\section{References}

[1] S. M. Wu and L. Y. Chan, "Performance utility-analysis of multi-state systems," IEEE Transactions on Reliability, vol. 52, no. 1, pp. 14-21, 2003.

[2] A. Lisnianski, "Extended block diagram method for a multistate system reliability assessment," Reliability Engineering and System Safety, vol. 92, no. 12, pp. 1601-1607, 2007.

[3] Z. W. Birnbaum, On the Importance of Different Components in a Multicomponent System in Multivariate Analysis, P. R. Krishnaiah, Ed., Academic Press, New York, 1969.

[4] W. Kuo and X. Zhu, Importance Measures in Reliability, Risk, and Optimization: Principles and Applications, John Wiley and Sons, 2012.

[5] H. E. Lambert, Fault Trees for Decision Making in Systems Analysis, Univ, Calif., Livermore, Berkeley, UC, 1975, Ph. D. dissertation. 
[6] W. E. Vesely, "A time-dependent methodology for fault tree evaluation," Nuclear Engineering and Design, vol. 13, no. 2, pp. 337-360, 1970.

[7] J. B. Fussell, "How to hand-calculate system reliability and safety characteristics," IEEE Transactions on Reliability, vol. R-24, no. 3, pp. 169-174, 1975.

[8] M. J. Armstrong, "Joint reliability-importance of components," IEEE Transactions on Reliability, vol. 44, no. 3, pp. 408-412, 1995.

[9] J. S. Hong, H. Y. Koo, and C. H. Lie, "Joint reliability importance of_k_ -out-of-_n_systems," European Journal of Operational Research, vol. 142, no. 3, pp. 539-547, 2002.

[10] S. B. Akers, "Binary decision diagrams," IEEE Transactions on Computers, vol. C-27, no. 6, pp. 509-516, 1978.

[11] P. N. Bibilo, "Decomposition of a system of incompletely specified Boolean functions defined with a binary decision diagram," Automation and Remote Control, vol. 75, no. 7, pp. 1173-1194, 2014.

[12] Y. Mo, "New insights into the BDD-based reliability analysis of phased-mission systems," IEEE Transactions on Reliability, vol. 58, no. 4, pp. 667-678, 2009.

[13] L. M. Bartlett and J. D. Andrews, "An ordering heuristic to develop the binary decision diagram based on structural importance," Reliability Engineering and System Safety, vol. 72, no. 1, pp. 31-38, 2001.

[14] R. Remenyte-Prescott and J. D. Andrews, "An enhanced component connection method for conversion of fault trees to binary decision diagrams," Reliability Engineering and System Safety, vol. 93, no. 10, pp. 1543-1550, 2008.

[15] C. Ibáñez-Llano, A. Rauzy, E. Meléndez, and F. Nieto, “A reduction approach to improve the quantification of linked fault trees through binary decision diagrams," Reliability Engineering and System Safety, vol. 95, no. 12, pp. 1314-1323, 2010.

[16] L. Xing and G. Levitin, "BDD-based reliability evaluation of phased-mission systems with internal/external commoncause failures," Reliability Engineering and System Safety, vol. 112, no. 4, pp. 145-153, 2013.

[17] X. Zang, N. Sun, and K. S. Trivedi, “A BDD-based algorithm for reliability analysis of phased-mission systems," IEEE Transactions on Reliability, vol. 48, no. 1, pp. 50-60, 1999.

[18] R. E. Barlow and A. S. Wu, "Coherent systems with multi-state components," Mathmatics of Operations Reserch, vol. 3, no. 4, pp. 275-281, 1978.

[19] A. Lisnianski, I. Frenkel, and Y. Ding, Multi-State System Reliability and Optimization for Engineers and Industrial Managers, Springer, London, UK, 2010.

[20] G. Levitin and A. Lisnianski, "A new approach to solving problems of multi-state system reliability optimization," Quality and Reliability Engineering International, vol. 17, no. 2, pp. 93-104, 2001.

[21] G. Levitin, L. Podofillini, and E. Zio, "Generalised importance measures for multi-state elements based on performance level restrictions," Reliability Engineering and System Safety, vol. 82, no. 3, pp. 287-298, 2003.

[22] A. Lisnianski, E. Levit, and L. Teper, "Short-term availability and performability analysis for a large-scale multi-state system based on robotic sensors," Reliability Engineering and System Safety, vol. 205, no. 1, pp. 107206-107209, 2021.

[23] A. Lisnianski, Application of Extended Universal Generating Function Technique to Dynamic Reliability Analysis of a
Multi-State System, 2nd SMRLO, Shamoon Coll Engn, Beer Sheva, Israel, 2016.

[24] J. E. Ramirez-Marquez and D. W. Coit, "Composite importance measures for multi-state systems with multi-state components," IEEE Transactions on Reliability, vol. 54, no. 3, pp. 517-529, 2005.

[25] B. Natvig and I. Ebrary, Multistate Systems Reliability Theory with Applications, John Wiley and Sons, Ltd, Chichester, UK, 2011.

[26] B. Natvig, "Measures of component importance in nonrepairable and repairable multistate strongly coherent systems," Methodology and Computing in Applied Probability, vol. 13, no. 3, pp. 523-547, 2011.

[27] J. Wu, T. S. Ng, M. Xie, and H. Z. Huang, "Analysis of maintenance policies for finite life-cycle multi-state systems," Computers and Industrial Engineering, vol. 59, no. 4, pp. 638-646, 2010.

[28] M. Zhang, "A heuristic policy for maintaining multiple multistate systems," Reliability Engineering and System Safety, vol. 203, no. 1, p. 107081, 2020.

[29] A. A. A. Ahmed and Y. Liu, "Throughput-based importance measures of multistate production systems," International Journal of Production Research, vol. 57, no. 2, pp. 397-410, 2019.

[30] C. D. Dao and M. J. Zuo, "Selective maintenance for multistate series systems with S-dependent components," IEEE Transactions on Reliability, vol. 65, no. 2, pp. 525-539, 2016.

[31] P. Do and C. Bérenguer, "Conditional reliability-based importance measures," Reliability Engineering and System Safety, vol. 193, no. 1, p. 106633, 2020.

[32] E. Borgonovo and G. E. Apostolakis, "A new importance measure for risk-informed decision making," Reliability Engineering and System Safety, vol. 72, no. 2, pp. 193-212, 2001.

[33] E. Borgonovo, "Differential importance and comparative statics: an application to inventory management," International Journal of Production Economics, vol. 111, no. 1, pp. 170179, 2008.

[34] E. Borgonovo, H. Aliee, M. Glaß, and J. Teich, "A new timeindependent reliability importance measure," European Journal of Operational Research, vol. 254, no. 2, pp. 427-442, 2016.

[35] H. Peng, D. W. Coit, and Q. M. Feng, "Component reliability criticality or importance measures for systems with degrading components," IEEE Transactions on Reliability, vol. 61, no. 1, pp. 4-12, 2012.

[36] S. Ahmadi, S. Moosazadeh, M. Hajihassani, H. Moomivand, and M. M. Rajaei, "Reliability, availability and maintainability analysis of the conveyor system in mechanized tunneling," Measurement, vol. 145, no. 1, pp. 756-764, 2019.

[37] T. Niu, F. Li, B. Hu et al., "Research on the inverse problem of reliability evaluation-model and algorithm," IEEE Access, vol. 9, no. 1, pp. 12648-12656, 2021.

[38] A. Mahmoud, "Economic allocation of reliability growth testing using Weibull distributions," Reliability Engineering and System Safety, vol. 152, no. 1, pp. 273-280, 2016.

[39] G. S. Mudholkar, K. O. Asubonteng, and A. D. Hutson, "Transformation of the bathtub failure rate data in reliability for using Weibull-model analysis," Statistical Methodology, vol. 6, no. 6, pp. 622-633, 2009.

[40] S. Y. Grodzensky, "Reliability models based on modified Weibull distributions," Measurement Techniques, vol. 56, no. 7, pp. 768-774, 2013. 
[41] W. T. Liu, Q. L. Zeng, L. R. Wan, and C. Wang, "A comprehensive method of apportioning reliability goals for new product of hydraulic excavator," Mathematical Problems in Engineering, vol. 2019, 11 pages, 2019.

[42] Q. Zeng, W. Liu, L. Wan, C. Wang, and K. Gao, "Maintenance strategy based on reliability analysis and FMEA: a case study for hydraulic cylinders of traditional excavators with ERRS," Mathematical Problems in Engineering, vol. 1, 11 pages, 2020.

[43] J. X. Liu, Z. Y. Jiao, F. X. Xian, and W. T. Liu, "Energy recovery and utilization system of excavator boom based on flow regeneration and balance theory," Journal of the Brazilian Society of Mechanical Sciences and Engineering, vol. 42, no. 1, pp. 1-11, 2020.

[44] J. Zhao, J. Na, and G. B. Gao, "Adaptive dynamic programming based robust control of nonlinear systems with unmatched uncertainties," Neurocomputing, vol. 395, pp. 5665, 2020.

[45] J. Zhao, Y. F. Lv, and Z. L. Zhao, "Adaptive learning based output-feedback optimal control of CT two-player zero-sum games," IEEE Transactions on Circuits and Systems II: Express Briefs, p. 1, 2021. 